\title{
Re-Opening the Silk Road to Transform Chinese Trade
}

\author{
Ning Mao ${ }^{1}$ and Michael McAleer ${ }^{2-6, *}$ \\ ${ }^{1}$ China-ASEAN International College, Dhurakij Pundit University, Bangkok, Thailand \\ ${ }^{2}$ Department of Quantitative Finance, National Tsing Hua University, Taiwan \\ ${ }^{3}$ Discipline of Business Analytics, University of Sydney Business School, Australia \\ ${ }^{4}$ Econometric Institute, Erasmus School of Economics, Erasmus University Rotterdam, Netherlands \\ ${ }^{5}$ Department of Quantitative Economics, Complutense University of Madrid, Spain \\ ${ }^{6}$ Institute of Advanced Sciences, Yokohama National University, Japan
}

\begin{abstract}
Under anti-globalization and isolationism, China is seeking to portray itself as a new leader for globalization under the banner of the Silk Road initiative. Meanwhile, China's traditional and comparatively advantaged industry, silk, has faced dire predicaments and challenges for long time, and needs a transformation in terms of initiatives. Throughout history, the prosperity arising from silk was supposed to represent a microcosm of Chinese society. This paper searches the breakthrough point to improve the current dilemma of Chinese silk enterprises; uses a Case Study for inductive reasoning that is feasible for marketing strategies; and provides a strategy to help Chinese silk enterprises to transform their market positioning and operating modes to obtain better development opportunities. The paper also analyzes the new external environment based on the "One Belt, One Road" principle, which is of crucial importance for the implementation of new marketing strategies.
\end{abstract}

Keywords: China, Silk, Company Strategy, National Strategy, Transformation, Chinese Trade.

\section{INTRODUCTION}

Throughout history, the Silk Road crossed the mountains and deserts to connect China and Europe. In the 19th Century, the German geologist Ferdinand Von Richthofen first coined the name Silk Road for the route. Silk products were always the most important goods in Chinese foreign trade, even compared with tea and chinaware. Based on a technical blockade, China had a monopoly in the silk business worldwide for nearly one thousand years. Then other countries gradually began to obtain the production process of silk. At the same time, lasting political and economic turmoil in China was such that the Chinese industry lost its dominant position in the silk market. In 1976, China began to implement economic reform policies, and has strongly promoted the development of the silk industry. During this period, Chinese manufacturing of finished silk goods exceeded that of the rest of the world (Schoeser, 2007).

In 2015, Chinese silk production comprised almost $84 \%$ of the world's total production. The Chinese silk industry has been challenged for several reasons in recent years: (i) many developing countries have lower labour and production costs; and (ii) there is a shortage

*Address of correspondence to this author at the Department of Quantitative Finance, National Tsing Hua University, Taiwan; Tel: +886-3-571-5131 ext. 62534; Fax: +886-3-562-1823; E-mail: michael.mcaleer@gmail.com

JEL: O24, P33, Q27. of high value-added products, over-dependence on overseas markets, and a lack of retail channels.

Silk is of historical significance and symbolic importance to China. For example, the Chinese government has selected the Silk Road to represent its own development strategy, such as "One Belt and One Road".

Special meaning is attached to the Silk Road Economic Belt and 21st Century Maritime Silk Road. The culture and historical genes of "One Belt and One Road" come from the old Silk Road, which takes Eurasia as its main region, and includes South-East Asia, Sub-continent, Middle East and Africa, with over 110 countries being encompassed.

China intends to invest billions of dollars in these areas, and to construct railways, ports and power grids. This strategy can be explained by the fact that the old Silk Road helped Chinese search for markets internationally. In the same vein, the new Silk Road (One Belt and One Road) is intended to help Chinese to create new markets as a way of transforming Chinese trade with international partners.

\section{CHINESE SILK INDUSTRY}

\subsection{Advantages of the Chinese Silk Industry}

The silk industry has been a special phenomenon in that many countries demand Chinese silk, even though 
there is not an established industrial chain. Developed countries have no silk manufacturing, while developing countries generally do not have qualified manufacturing opportunities. For example, the major silk-producing countries in the world are China, India, Uzbekistan, Brazil, Thailand, Vietnam, and Iran. However, the major silk consumers of the world are USA, Italy, Japan, India, France, United Kingdom, Germany and UAE.

Only India appears as a consumer and a producer of silk products, with an absolute emphasis on Sari, which is female apparel from the Indian subcontinent. Sari consists of a drape, varying from five to nine yards in length and two to four feet in breadth, that is typically wrapped around the waist, with one end draped over the shoulder, baring the midriff (Boulanger, 1997).

Preeya (2013) identified silk production as being categorized into three main stages, namely: (i) the upstream industry covers sericulture farming, silk rearing and silk reeling, in China, with a large majority of such farmers being located in the East coast; (ii) the weaving, dying and printing has constituted the midstream industry, a process that is either done by hand in the villages or processed by large machines in the industrial sector; and (iii) the downstream industry, which includes the design, production, retailing and marketing of various silk products, such as clothing, bedding and decorations. Chinese accounted for $84 \%$ of global raw silk production and over $90 \%$ of the world export market, with 20 million workers in the industry. In short, China is the only country worldwide that has an integrated silk industry.

\subsection{Challenges and Dilemma}

The Chinese silk industry has been challenged for several reasons in recent years: (i) many developing countries had lower labor, land and production cost; and (ii) shortage of high value-added products, overdependence on overseas markets, as well as a lack of retail channels. Over $80 \%$ of silk products are exported to overseas market, therefore, when an economic downturn or financial crisis occurs, the Chinese silk industry faces devastating blows. Also, industry relies on low labour, land and raw material costs, so that when the government promulgates new Labor Law to increase wages, most silk enterprises will lose their competitive edge. The series of problems in silk industry is completely consistent with problems of whole Chinese manufacturing.

\section{(1) Dilemma of Chinese's Silk Industry}

(i) Cocoon prices are high (labor, land and material costs are determined)

(ii) Silk prices are high (cocoon prices are determined)

(iii) Silk fabric prices are low (market demands is determined)

(iv) Silk supply function, which depends on prices and cost factors, among others.

(2) Dilemma of Chinese Manufacturing

(i) Labor, land and raw material costs are high (stage of development is determined)

(ii) Enterprise production cost is high (labor, land and raw materials are determined)

(iii) Products prices are low (market demand is determined)

(iv) Silk demand function, which depends on prices and income, among others.

As a result, decreasing market demand has reduced the prices of products (or silk fabrics), but the growing costs of labor, land and raw material (or cocoon) have also promoted the enterprises' production cost (or silk price). Macroeconomic factors have deeply influenced Chinese enterprises, and not just the silk industry. Creating new markets might allow a solution to such difficulties.

New markets are possible from the sea (that is, the Maritime Silk Road), and also from the land (namely, the Silk Road Economic Belt). However, the method of creation is the same, which is to use Chinese capital to create markets for Chinese requirements. As an illustration, during the Greek debt crisis period, China provided large loans to Greece, but on the condition that Greece was required to purchase ships from Chinese shipyards.

Today, over three thousand silk enterprises exist in China. However, over $90 \%$ of these are township or village enterprises that use price wars to destabilize market shares and seriously disrupt normal market prices. In general, new market creation and product innovation are the most important approaches to solve the dilemma. As in internet marketing and innovation 
design, for a long time the Chinese silk industry has been struggling in this dimension.

\section{ILLUSTRATION}

ZheJiang and Jiaxin Silk Crop, Ltd. (with abbreviated name JSCL, SHE: 002404) are the only two listed companies in the China silk industry, and it is typical of research. JSCL is a labour-intensive enterprise, with over $80 \%$ of its products exported to overseas markets annually. In recent years, its revenues have continued to fall, but operating costs increased substantially from $5.48 \%$ in 2013 to $10.22 \%$ in 2015. The corporate annual financial statement in 2015 indicated that, during the previous year, corporate annual gross revenue was $¥ 2.01$ billion, annual total cost was $¥ 1.94$ billion, total costs were $95 \%$ of gross revenue, and profits charged against the bank annual interest was 4.8\% (Jiaxin Silk Crop, Ltd. Audit Reports and Financial Statements, 2015).

The causes of JSCL's problems are as follows: (i) dependence on the export-oriented economy; (ii) operating by $\mathrm{B} 2 \mathrm{~B}$ transactions, without characteristics of goods; and (iii) lacking loyal consumer and brand awareness. Therefore, company issues have been proposed, such as how to: (a) reduce the dependence on exports; (b) propose a rational and improved business model; and (c) create the characteristics of silk goods and establish an appropriate brand image.

\subsection{Dilemma of Traditional Transformation Approach}

The domestic market can increase the enterprise's revenue and reduce losses through exchange rate fluctuations. Increasing brand visibility in domestic markets will also improve the confidence of investors, and assist silk enterprises to obtain additional capital resources. However, the domestic market is different from the export market, as the former needs ready-touse products to replace the products of foreign brand dealers. International marketing does not need companies to establish and maintain distribution channels, whereas domestic marketing needs such channels.

Furthermore, some researchers have found that, compared with other countries, China has more Parvenus and Poseurs consumers (Gao, 2009; Luxury 4P taxonomy, Han, Nunes and Dreze, 2010; Khan, 2015; McAleer and Mao, 2017). Yang (2012) indicated that the wealthy group is comprised of Patricians and
Parvenus. Patricians possess significant wealth, like inconspicuously branded, low in consumption-related need for status. Parvenus also possess significant wealth, but seek status through consumption, and choose using conspicuous signals to express their economic power.

The less affluent group is composed of Poseurs and Proletarians. Poseurs, like Parvenus, seek status and prefer conspicuous products, but do not possess sufficient wealth to afford authentic goods. Proletarians are less affluent and low in need for status, so this group does not have a strong motivation to purchase either conspicuous or inconspicuous products (Yang, 2012).

Porter (2003) indicated developing economies seek sustainable high income levels, need from isolated firms to an array of clusters, and upgrade the breadth and sophistication of clusters to more advanced activities. Among the central recommendations were to strengthen brands, encourage linkages, focus on innovation, and develop a shared vision between the public and private sectors.

A brand is essentially a promise, as products are made in factories, whereas brands are created in the mind, such that brands represent the attributes, quality, price, reputation, image, and self-expression of the underlying products. The brand attribute must be focused on a narrow and specific product range, such as underwear experts or jeans masters, in order to convince and inform customers about the qualities of the companies and their associated products.

Hui and Zhou (2002) proposed an integrative model and believed that three variables, namely Country-ofOrigin (COO), Brand Name and Price, were the major predictors for overall product evaluation and purchase intentions. COO refers to quality, prestige, and workmanship, while brand name represents value and equity. According to Hui and Zhou's (2002) model, except for the price element, consumers have a high anticipation for a product's brand name and COO, regardless of their culture, status and psychological needs.

Han (2005) explored the relative importance of $\mathrm{COO}$ and brand name on Taiwanese consumers' perception of products, and indicated the influences of incongruent information between the $\mathrm{COO}$ and brand origin impact on consumers' product evaluation and purchase intentions. In other words, at the present 
stage, the slogan Made in China is relatively low by way of reputation, so it is essential to raise the brand to enter the mid-to-high marketing strata, which may well be difficult for JSCL.

\subsection{Impact of Cultural Dimension}

According to the Hofstede cultural dimension theory (Hofstede, 1984), China is a typical collectivist country, so that interpersonal effects are expected. Therefore, JSCL must consider interpersonal effects more, such as the Veblen, Snob, and Bandwagon effects. Veblen's (1899) theory of the leisure class is the foundation of status consumption research, and sheds light on how people use wealth and goods to compete with each other, as well as to bolster their social status.

Yang (2012) indicated, in a pecuniary competition system, people try to distance themselves from those in a lower class, while mimicking the behavior of others in a higher class. Simmel (1904) proposed the upperclass theory of fashion. First, lower classes adopt the status symbols of classes above them as they seek to climb the ladder of social status. Second, the upper class abandons fashions that are adopted by the lower classes as they attempt to distinguish themselves from the lower classes.

In conclusion, in a collectivist country, clothes and accessories are not just to satisfy consumer's functional needs, but also to cater to consumer's psychological needs. Frequently, $\mathrm{COO}$ and brand names will influence consumers' product evaluation and purchase intentions more than the design, quality and workmanship. JSCL needs to understand that consumers have different psychological needs in the domestic market. At present, most Chinese consumers lack the means and motivation to purchase domestic high-end brands.

In any event, the domestic market is more concerned with the relationship between enterprises and consumers. For example, boutiques, franchise stores, department stores, and warehouse stores are four primarily retail channels, with each distribution channel having established a different relationship between sellers and buyers. If JSCL chooses department stores as channels, the company image will be established according to the associated store image. Franchise stores and warehouse stores always operate according to middle brands and fast fashion. Upmarket department stores tend to prefer international brands to domestic brands for self- positioning, which leads to another competitive disadvantage for JSCL.

Push and pull factors have emerged as an important method for interpreting retailers' motives for expanding into domestic and foreign retail markets. Retailers are pulled towards a foreign market and/or are "pushed" out of their home market in order to further their growth objectives (Hines, 2007). Like $\mathrm{JSCL}$, it presently lacks the reputation and loyalty of consumers in the domestic market, so it is hard to cooperate with upscale department stores or traditional department stores in order to establish its enterprise image. Promoting the brand reputation overseas can improve the company image from the perspective of domestic consumer psychology.

\subsection{Future Transformation Approach}

The traditional transformation approach needs mass economic inputs, so that it is not suitable for every company, especially for struggling companies such as JSCL. Internet B2C commerce reduces the cost of transactions by allowing customers to access information more easily about different products and sellers. Compared with mass upfront investment to enter the bricks and mortar retail markets, the ecommerce platform has helped many financially poor companies to run businesses.

Alibaba (NYSE:BABA) is a famous example, as it has helped over one million Chinese families to enter the middle class, and also promotes the Chinese package industry, the logistics industry, and even the fast food industry. However, the B2C or C2C platform cannot solve all the underlying problems, especially product differences relating to consumer needs, such as haute couture or fast fashion.

Compared with the IT industry, some traditional industries in China are stagnant. The Chinese Government has guided traditional industries to develop intelligent production. Examples include "Created in China" to replace "Made in China", but asymmetric information is a problem to impede these good intentions. In the past, manufacturers were aware that meeting every customer's needs was an impossible task. Therefore, as in the case of JSCL, concentrating on only a limited number of products cannot possibly meet all the requirements of consumers.

Employing Industry 4.0 could possibly change this situation, as Industry 4.0 provides automation and data 
exchange in manufacturing technologies, including cyber-physical systems and cloud computing. Based on this technology, customers and enterprises can connect with each other at a very low cost, so that demand might be enhanced significantly. Nowadays, consumers increasingly prefer personalized products, but personalized products frequently have extremely small requirements that need the Industry 4.0 platform to capture customer needs and rapid production accurately.

China has a complete silk industrial chain and huge industry scale, so that rapid production is an obvious advantage of Chinese enterprises. A remaining problem is how to expand and link systems such as ERP (Enterprise Resource Planning) and MES (Manufacturing Execution System), and allow enterprises from the complete automation and portion information period to move toward complete automation and information. JSCL needs to establish an online service platform, and allow the platform to connect with production equipment, use the RFID (Radio Frequency Identification) to cover the product information, and then use the information for intelligent production.

JSCL's role should be like an intelligent enterprise, receiving the information from domestic or overseas consumers, and then producing customers' orders. When the online information system and automated production system are combined, JSCL could reposition itself as a cloud enterprise. JSCL might only focus on silk product innovation and service upgrades, so it would not need to develop its own server and online platforms. A direct hiring of the cloud service would save time and money. Meanwhile, JSCL could also accept orders from other online platforms as a cloud silk factory.

A future transformation approach can provide possibilities to help JSCL to overcome the brand and characteristic goods issue to a certain extent, but compared with these two issues, seeking new markets may be more important and profitable. One Belt and One Road tries to use Chinese capital to create a safer external environment and greater business opportunities. Based on previous research, most of the major silk consumers of the world, such as Italy, India, France, United Kingdom, Germany and UAE, are covered by the "Silk Road Economic Belt" strategy. With regard to India, it has the Sari custom and a huge population, with a corresponding wide market potential.

\subsection{Future Strategy Integrated National Strategy}

The Silk Road Economic Belt strategy has been divided along road countries at three levels. The first level is called the Core Area, with the Chinese Government expending funds to promote national security, such as strike ethnic separatism and terrorists. In this area, the development of economic cooperation and trade is a secondary aim as a lower population and per capita incomes cannot provide a larger market.

The second level is called the Important Area, including resource-rich countries, such as Russia, Iran and Saudi. These countries possess oil and other resources, whereas China possesses excess iron and steel, idle foreign exchange funds, and advanced technology. Reasonable international exchanges can be beneficial to both parties. Furthermore, this area also encompasses highly-populated countries like Pakistan and India.

Generally, highly populated countries have equally high consumption levels, and hence can establish and present huge markets. However, based on a weak infrastructure and lower income, most Indians still live in the basic economy, do not benefit from international division of labour, or enjoy low prices and high quality Chinese products and services. The "One Belt, One Road" strategy has a project to invest billions dollars to construct railways, ports and power grids in this area, through the Asian Infrastructure Investment Bank. If it succeeds, this would be highly profitable for Chinese enterprises, especially for the silk industry.

\subsection{International Trade}

Compared with China, India has more Poseurs and Proletarians consumers (Yang, 2012; Han, Nunes and Dreze, 2010). These two groups of consumers have lower level of lust for status consumption, and are more focused on functional needs than other product's added-value. Hofstede $(2001,2017)$ indicated that India, with an intermediate score of 48 , is a society with both Collectivistic and Individualist traits.

The collectivist side means that there is a high preference for belonging to a larger social framework in which individuals are expected to act in accordance to the greater good of one's defined in-group(s). In such situations, the actions of the individual are influenced by various concepts, such as the opinions of one's family, extended family, neighbors, work group, and 
other wider social networks with which one has some affiliation. For a collectivist, to be rejected by one's peers, or to be thought of as lowly by one's extended and immediate in-groups, leaves them rudderless and with a sense of intense emptiness.

The Individualist aspect of Indian Society is seen as a result of its dominant religion/philosophy, namely Hinduism. Hindus believe in a cycle of death and rebirth, with the manner of each rebirth being dependent upon how the individual lived their preceding life. Individuals are responsible for the way in which they have led their lives, and the impact it will have upon their rebirth. Such a focus on individualism interacts with the otherwise collectivist tendencies of Indian society, which leads to its intermediate score on this dimension (Hofstede, 2001). As a result, compared with a classic collectivistic country, such as China, the interpersonal effect is much weaker between Indian individuals. Consequently, the lack of brand reputation and recognition is an advantage to Chinese silk enterprises, which have greater opportunities to offset the resulting gap.

Owing to the sensitive nature of the Tibet Territorial issue (which China calls Southern Tibet, and India calls Arunachal Pradesh), and the standpoint of Pakistan, China and India have many political conflicts, with cooperation and contacts in politics regarded as relatively unimportant. Although the Chinese Government has stated that the New Silk Road is not political, it has nevertheless run into opposition from India due to a section of the Road in Pakistan, known as the China-Pakistan Economic Corridor, where some projects run through the disputed Kashmir region.

Therefore, China must strengthen both business and cultural cooperation with India, and to seek to disarm and create a peaceful environment to protect the crucial economic trading strategies.

China has been using the Three Approaches to maintain economic growth in recent decades, such as Railway Construction, Road Construction and Infrastructure Construction (RRI). In reality, these three approaches have created new markets and integration of urban and rural markets. "One Belt One Road" can be regarded as RRI 2.0 or RRI overseas version.

RRI 2.0 could be considered as macroeconomic policy, but it will create more new market shares at the microeconomic level. RRI 2.0 can also transform current markets and market shares, such as from handicrafts to manufacturing and industrialization. Releasing the stock of funds in RRI cannot increase the quantity of money, so such a strategy should not be the cause of higher inflation.

\subsection{Target Marketing}

In recent years, CHINDIA (China, India) and BRIC (Brazil, Russia, India, and China) have been mentioned in the media and by politicians as both collective regions and countries possess huge population bases and development potential. Silk as a fiber was first discovered by the Chinese, but India also has a rich and complex history in silk production and silk processing. China breeds a greater number of bivoltine silkworms, which provide a higher quality of silk, but also a lower yield in silk. India breeds a greater number of multivoltine silkworms, which is lower in the quality of silk, but also a higher yield in silk. However, compared with China's industrial silk production processes, Indian silk production remains essentially a manual process.

India is the second largest producer of raw silk, and the largest consumer of raw silk and silk fabrics, as the consumption of raw silk (around 28,740 MT, 2013) exceeds production. The additional requirement of around 5,700 MT (2013) of silk is imported mainly from China. Through the direct exporting of raw silk, China has gained limited benefits, especially as the Indian Government has launched continuous anti-dumping measures since 2002 to try to limit China's raw silk and silk fabric markets.

India has the unique distinction of being the only country producing all five known commercial silks, namely Mulberry, Tropical Tasar, Oak Tasar, Eri, and Muga. Mulberry sericulture is mainly practised in five states, namely Karnataka, Andhra Pradesh, Tamil Nadu, West Bengal, and Jammu Kashmir jointly account for about $97 \%$ of the total mulberry silk production in the country. Non-Mulberry has been called Vanya Silk; Tropical Tasar is produced in Central India's Chhattisgarh Jharkhand, Odisha; and Oak Tasar is produced in Uttarakhand State. India is the biggest producer of Eri. Muga with its golden yellow glitter, is unique and a prerogative of India. Both Muga and Eri are produced in Assam.

From 1980, the World Bank's agriculture sector supported the Karnataka Sericulture Project (1980-88) in India, which was intended to help promote employment and enhance productivity. Subsequently, the Indian Government launched the National 
Sericulture Project (1989-96). After completion of the two projects, Indian Central Committee found the Silk Catalytic Development Programme. Based on linear analyses of the data before and after three projects, $\mathrm{Li}$ (2008) indicated that government investment had an obvious linear correlation on Silk Total Output and Silk Export Quantity. Therefore, integrated macroeconomic and microeconomic research suggests that the huge investment of "One Belt One Road" will stimulate the silk market and international silk marketing.

Compared with other export commodities, China's silk has a greater competitive edge, with price elasticity of -0.3825 , which might be viewed as a relatively low elasticity, so that a lower price cannot increase export volume. Previously, the primary competitive advantage of Chinese silk was price. This is a similar situation to that of India, which was also able to promote silk textile competitiveness and the creation of new market possibilities.

Through analysis of PEST, in political terms, India had a strict separation of state and religion, based on British Parliamentary Democracy, with no Military Coup de tat. Morever, the official Civil System was not impacted by regime changes.

In terms of economic factors, India's financial system may have been superior to that of China, with private companies finding it more straightforward to obtain financial loans, with abundant labor and growth dividends.
In terms of social factors, India has long been under the influence of religion, so that the Indian traditional culture has been preserved. Sari is still the main garment for Indian women. The use of the English language is another advantage in India, as foreign enterprises have developed English online platforms to meet the needs of Indian consumers of silk and other products.

In terms of technological factors, India can provide advantageous internet technology that is supported with operational maintenance. This can reduce the cost for foreign companies, with high technical imagery based on internet technology that has excellent chances to advance economic and social growth.

\section{CONCLUSION}

Regardless of production technologies or industry scale, the Chinese silk industry still has numerous and obvious advantages. The traditional operational mode has reached a bottleneck, which cannot release the enormous potential of industry. In fact, macroeconomic strategies always seem to change the microeconomic environment. For example, hundreds of years ago, the Silk Road crossed the mountains and deserts to connect China and Europe, and found new markets thousands of miles away. Nowadays, the existing markets that were found a long time ago are such that further development needs to occur to create and enhance new markets through international trade.

Table 1: Economic Analysis of Silk Road Economic Belt

\begin{tabular}{|c|c|c|c|c|c|c|c|c|c|c|}
\hline \multirow[t]{2}{*}{ Level } & \multirow[t]{2}{*}{ Region } & \multirow{2}{*}{$\begin{array}{c}\text { Strategic } \\
\text { Focus }\end{array}$} & \multirow[t]{2}{*}{ Main Area } & \multirow{2}{*}{$\begin{array}{c}\text { Population } \\
\text { (Million) }\end{array}$} & \multirow{2}{*}{$\begin{array}{c}\text { GDP } \\
\text { (Total) } \\
\text { (Billions } \\
\$ \text { ) }\end{array}$} & \multirow{2}{*}{$\begin{array}{c}\text { GDP } \\
\text { (Per } \\
\text { Capita) } \\
\text { (Hundred } \\
\$ \text { ) }\end{array}$} & \multicolumn{2}{|c|}{ Export (\%) } & \multicolumn{2}{|c|}{ Import (\%) } \\
\hline & & & & & & & Proportion & $\begin{array}{c}\text { Proportion } \\
\text { For } \\
\text { China }\end{array}$ & Proportion & $\begin{array}{c}\text { Proportion } \\
\text { For } \\
\text { China }\end{array}$ \\
\hline Core Area & $\begin{array}{l}\text { Central } \\
\text { Asia } \\
\text { Economic } \\
\text { Belt }\end{array}$ & $\begin{array}{l}\text { Security } \\
\text { Stability } \\
\text { Energy } \\
\text { Resources }\end{array}$ & $\begin{array}{l}\text { 1. Kazakhstan } \\
\text { 2. Kyrgyzstan } \\
\text { 3. Tajikistan } \\
\text { 4. Uzbekistan } \\
\text { 5.Turkmenistan }\end{array}$ & $\begin{array}{l}16.8 \\
5.6 \\
8.0 \\
29.8 \\
5.2\end{array}$ & $\begin{array}{l}2000 \\
65 \\
70 \\
511 \\
337\end{array}$ & $\begin{array}{l}120 \\
11.6 \\
8.7 \\
17.2 \\
65.1\end{array}$ & $\begin{array}{l}0.5 \\
0.01 \\
0.01 \\
0.06 \\
0.09\end{array}$ & $\begin{array}{l}17.9 \\
3.6 \\
-- \\
-- \\
--\end{array}$ & $\begin{array}{l}0.24 \\
0.03 \\
0.02 \\
0.06 \\
0.05\end{array}$ & $\begin{array}{l}16.8 \\
22.5 \\
-- \\
-- \\
--\end{array}$ \\
\hline $\begin{array}{l}\text { Important } \\
\text { Area }\end{array}$ & $\begin{array}{l}\text { Surround } \\
\text { Central } \\
\text { Asia } \\
\text { Economic } \\
\text { Belt }\end{array}$ & $\begin{array}{l}\text { Energy } \\
\text { Resources } \\
\text { Economy } \\
\text { Trade }\end{array}$ & $\begin{array}{l}\text { 1. Russia } \\
\text { 2. India } \\
\text { 3. Iran } \\
\text { 4. Saudi Arabia } \\
\text { 5. Pakistan }\end{array}$ & $\begin{array}{l}143.5 \\
1236.7 \\
76.4 \\
28.3 \\
179.2\end{array}$ & $\begin{array}{l}20148 \\
18417 \\
5141 \\
7110 \\
2312\end{array}$ & $\begin{array}{l}140 \\
14.9 \\
68.2 \\
251.2 \\
12.9\end{array}$ & $\begin{array}{l}2.88 \\
1.60 \\
0.57 \\
2.11 \\
0.13\end{array}$ & $\begin{array}{l}6.4 \\
5.1 \\
4.0 \\
-- \\
10.6\end{array}$ & $\begin{array}{l}1.80 \\
2.63 \\
0.31 \\
0.84 \\
0.24\end{array}$ & $\begin{array}{l}15.4 \\
11.1 \\
10.3 \\
9.7 \\
15.3\end{array}$ \\
\hline $\begin{array}{l}\text { Development } \\
\text { Area }\end{array}$ & $\begin{array}{l}\text { Eurasia } \\
\text { Economic } \\
\text { Belt }\end{array}$ & $\begin{array}{l}\text { Economy } \\
\text { Trade } \\
\text { Science } \\
\text { Technology }\end{array}$ & 1. EU & 510.0 & 166037 & 329.5 & 15 & 8.5 & 15.38 & 16.2 \\
\hline
\end{tabular}

Data Sources:

1: Table Population and GDP data from World Development Indicators.

2. Table Export and Import data from WTO 2012. 
The "One Belt One Road" strategy is intended to connect South-East Asia, South Asia, Middle East, Africa and Europe, and also assist a large number of developing countries to construct railways, ports and power grids to improve their economies. This makes it possible for Chinese enterprises to excavate new markets in hitherto unknown lands. Online platforms have helped many poor Chinese individuals economically, so there is reason to expect such to help Chinese enterprises in new markets. Both industry chains and industry scale are advantageous for the Chinese silk manufacturing industry. The use of manufactured goods to replace raw materials is also greatly needed.

How to find the right way of exerting these advantages should be more important than how to recognize them. New modes and thinking provide a feasible way of developing struggling Chinese enterprises, including the silk industry. The "One Belt One Road" policy will provide funds to help many countries to improve their infrastructure construction, establish local online platforms, and to use the new logistics and delivery networks as a key strategy of Chinese silk enterprises.

\section{SUPPORT}

For financial support, the second author acknowledges the Australian Research Council and the National Science Council, Ministry of Science and Technology (MOST), Taiwan.

\section{REFERENCES}

Boulanger, Chantal, "Saris: An Illustrated Guide to the Indian Art of Draping”, New York: Shakti Press International, 1997.
Gao, Ling. "Understanding Consumer Purchasing Behaviour Regarding Luxury Fashion-Related Goods in China", Hong Kong Polytechnic University, 2009.

Han, Young Jee, Joseph C Nunes and Xavier Drèze, "Signaling Status with Luxury Goods: The Role of Brand Prominence", Journal of Marketing, 74(4), 2010, 15-30. https://doi.org/10.1509/jmkg.74.4.15

Hines, T. and Bruce, M. Fashion Marketing, Routledge, 2007.

Hofstede, Geert, Culture's Consequences: International Differences in Work-Related Values. Vol. 5, Sage, 1984.

Hofstede, Geert H and Geert Hofstede, Culture's Consequences: Comparing Values, Behaviors, Institutions and Organizations Across Nations, Sage, 2001.

Hui, Michael K. and Lianxi Zhou, "Linking Product Evaluations and Purchase Intention for Country-of-Origin Effects", Journal of Global Marketing, 15(3-4), 2002, 95-116. https://doi.org/10.1300/J042v15n03_05

Jiaxin Silk Audit Reports and Financial Statements, 2015.

Khan, Omera, "Luxury Consumption Moves East", Journal of Fashion Marketing and Management, 19(4), 2015, 347-359. https://doi.org/10.1108/JFMM-10-2014-0076

McAleer, M. and N. Mao (2017), "Theravada Buddhism and Thai Luxury Fashion Consumption", Journal of Reviews on Global Economics, 6, 58-67. https://doi.org/10.6000/1929-7092.2017.06.05

Patichol, Preeya, Winai Wongsurawat and Lalit M. Johri, "Upgrade Strategies in the Thai Silk Industry: Balancing Value Promotion and Cultural Heritage", Journal of Fashion Marketing and Management, 18(1), 2014, 20-35. https://doi.org/10.1108/JFMM-09-2011-0059

Porter, Michael E., Thailand's Competitiveness, Creating the Foundations for Higher Productivity, National Economic and Social Development Board, 2003.

Schoeser, Mary, Silk, Yale University Press, 2007.

Simmel, Georg, "The Sociology of Conflict. I", American Journal of Sociology, 9(4),1904, 490-525. https://doi.org/10.1086/211234

Veblen, Thorstein, The Theory of the Leisure Class: An Economic Study in the Evolution of Institutions, 1899.

Yang, Wan, "The Impact of Status Seeking and Product Type on the Purchase of Luxury Goods and Luxury Experiential Services", Pennsylvania State University, 2012.

Received on 16-02-2017

Accepted on 13-05-2017

Published on 09-06-2017

DOI: https://doi.org/10.6000/1929-7092.2017.06.21

(C) 2017 Mao and McAleer; Licensee Lifescience Global.

This is an open access article licensed under the terms of the Creative Commons Attribution Non-Commercial License (http://creativecommons.org/licenses/by-nc/3.0/) which permits unrestricted, non-commercial use, distribution and reproduction in any medium, provided the work is properly cited. 